\title{
Organic Communications
}

A scientific open access journal in the field of synthetic organic chemistry and polymers.

Volume: 13 Year: 2020 Issue: 4 October-December

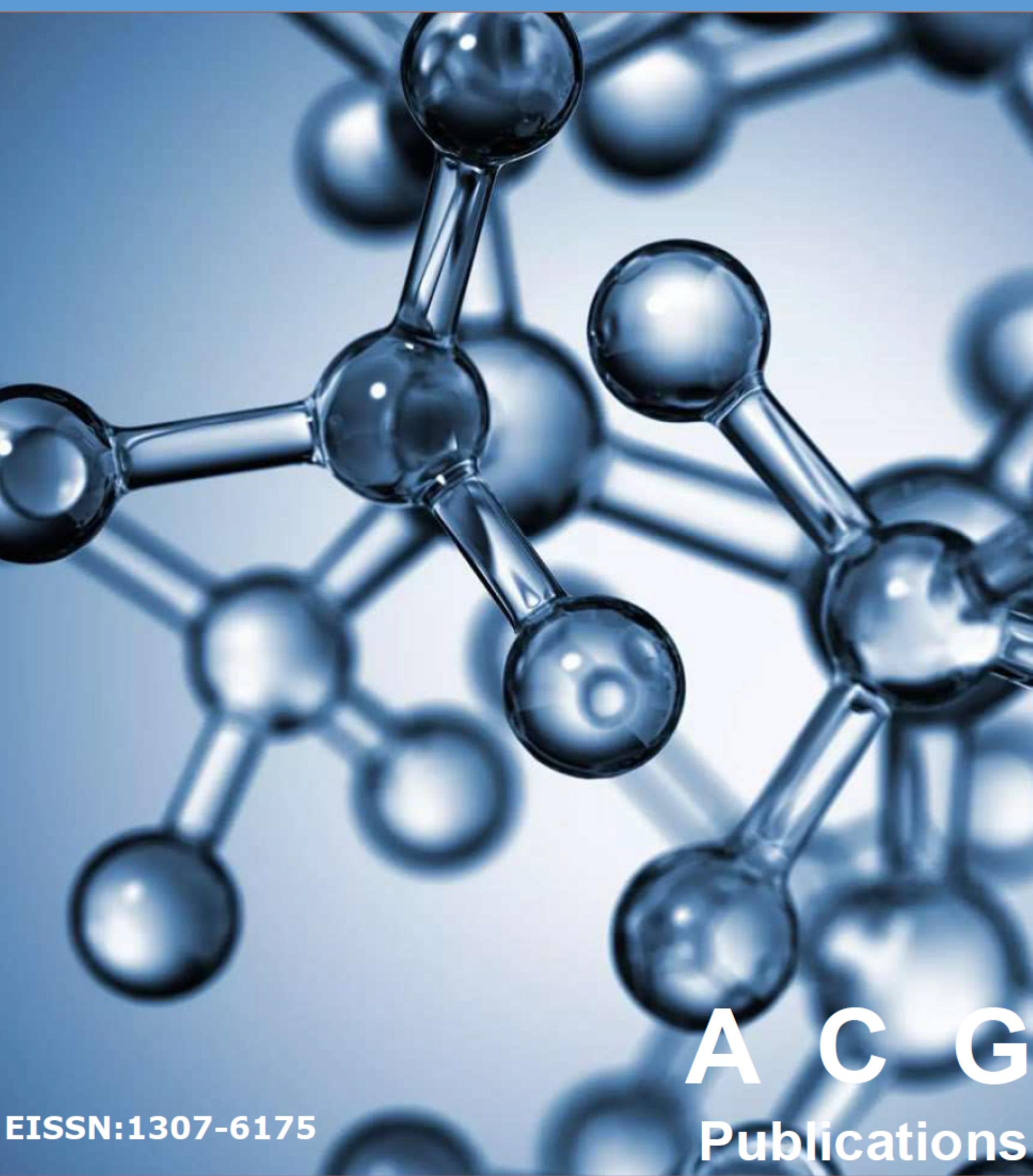




\section{Editor-in chief}

\section{Editor-in-Chief Hasan Seçen}

Review Article and Book Review Editor Turan Ozturk

Synthetic Polymer Section Editor Mehmet S. Eroglu

Co-Editor-in-Chief Ahmet C Goren

\section{Editors}

$\begin{array}{ll}\text { Siméon Arseniyadis } & \text { Levent Artok } \\ \text { Erkan Baloğlu } & \text { Udo H. Brinker } \\ \text { Necdet Coşkun } & \text { Arif Daştan } \\ \text { Timothy C Gallagher } & \text { Ahmet C. Gören } \\ \text { Illhami Gülçin } & \text { Turgut Kılıç } \\ \text { Sambasivarao Kotha } & \text { Fuk Yee Kwong } \\ \text { Peter Langer } & \text { Nurettin Mengeş } \\ \text { Turan Ozturk } & \text { Clovis Peppe } \\ \text { Brindaban C. Ranu } & \text { Pu Shouzhi } \\ \text { Cihangir Tanyeli } & \text { Yavuz Taşkesenligil } \\ \text { Wolfgang Voelter (2007-2020) } & \text { John Warren } \\ \text { Adi Wolfson } & \text { Mohammad Ali Zolfigol }\end{array}$

\section{Language Editors}

Turan Ozturk

Zeynep Sadak

\section{Abstracting \& Indexing}

Organic Communications is abstracted and Indexed in: Chemical Abstracts Service, EBSCOhost, ProQuest, Google Scholar, Index Copernicus, CrossRef, SCOPUS, ESCI Web of Science by Clarivate Analytics (formerly Thomson Reuters), $i$-Journals; $i$-Focus.

\section{Publisher}

\section{ACG Yayıncılık Basın Yayın Sanayi ve Ticaret Limited Şirketi}

Yenikent Mahallesi, Fırat Caddesi, 1/3, Gebze, Kocaeli, İstanbul, Türkiye

+90850 3050572 - www.acgpubs.org - info@acgpubs.org

$2020 @$ ACG Publications. All Rights Reserved

\section{Instruction For Authors}

Preparation of Manuscripts

Manuscripts should be prepared in English using a word processor.

Review Articles are critically evaluated on the specific area in organic synthesis and synthetic polymers. If you would like to contribute to the journal with a review article, the authors must initially contact to Professor Turan Ozturk, as such articles 
are normally invited.

Original Articles are manuscripts describing new synthesis strategies and developments in organic synthesis and synthetic polymers. The synthesis of nano materials and their properties and application reports are also welcome to the journal. These manuscripts should reflect completed investigations rather than fragmentary parts of a larger study. In order to reduce manuscript length, specific experimental details, NMR and HRMS (please check for the sample) spectra should be made available as supplementary material from the corresponding author for the novel compounds, at least one representative for each molecule group.

Authors are must use template (Template file for article: Please click to open template file ) for the preparation of manuscripts.

1. Introduction

2. Experimental

3. Results and Discussion

4. Conclusion

Acknowledgements/Supporting Informations

References.

Communications (1-8 pages) and Short Communications (1-6 pages) are suitable for reporting the urgent results of the large study, synthesis of a limited amount of novel compounds with known methodology and any important biological activity/application reports. Manuscripts describing routine synthesis of limited amounts of analogs without any biological assessment or application are generally not acceptable. Communications should be kept to a maximum of eight pages, including references. In order to reduce manuscript length, specific experimental details and NMR and HRMS (please check for the sample) spectra must be made available as supplementary material from the corresponding author for new compounds.

Authors are must use template (Template file for communications: Please click to open template file) for the preparation of manuscripts.

1. Introduction

2. Background

3. Experimental

4. Present Study

5. Conclusion

Acknowledgements/Supporting Informations

References

Special Issues and Book reviews are collections of articles on the specific topics in areas related to synthetic organic chemistry. Authors for the special topics must apply to review editor Professor Turan Ozturk.

As the manuscript language is English, any author who is not fluent enough in English is encouraged to consult a fluent colleague or a paid editing service for the preparation of the manuscripts. Manuscripts having language deficiencies, i.e. grammar, fluency, etc., create heavy problems during the review process. Such manuscripts might be returned to the authors for correcting the language deficiencies.

Novelty statements of submitted manuscript must be provided as MS word file item by item. The maximum item should be 6 for the novelty statement.

A graphical abstract must be provided during submission. The dimensions of the graphical abstract must be $6.5 \mathrm{~cm}(\mathrm{~h}) \mathrm{x}$ $12.5 \mathrm{~cm}$ (I). Please do not use the portrait version of graphical abstract. The graphical abstract must briefly show the contents of the abstract. Only structure of compound or picture of species not allowed for the graphical abstract.

Manuscripts submitted to ACG publications are routinely screened by a software to check the originality of the submitted articles. It should be noted that ACG publications are committed to deterring plagiarism and selfplagiarism. A plagiarism report must be uploaded during submission of manuscript.

Title of the manuscript should be as brief as possible and typed to the template file with affiliation and addresses of all the authors, including corresponding author with an asterisk. ORCID of all authors should be added as shown in the template of manuscripts. The e-mail address, phone and fax numbers of the corresponding author should be provided as a footnote on the title page. Abstracts of all kinds of submissions should be prepared with a maximum 200 words.

Authors must adhere to SI units. When using a word which is or is asserted to be a proprietary term or trade mark authors must use the symbol ${ }^{\circledR}$ or TM or alternatively a footnote can be inserted using the wording below:

References must be given as: 
Periodicals: (i) Surname(s) and Initial(s) of author(s) (authors separated by semi-colons), (ii) Title(s) of article, (iii) Title of the periodical abbreviated according to the international abstract list of journals and in italics, (iv) Year of publication in bold, (v) Volume number in italics, (v) Page numbers (first and last pages).

Baran, A.; Kazaz, C.; Secen, H.; Sutbeyaz, Y. Synthesis of haloconduritols from an endo-cycloadduct of furan and vinylene carbonate. Tetrahedron 2003, 59 (9), 3643-3648.

Karaman, I.; Gezegen, H.; Gurdere, M. B.; Dingil, A.; Ceylan, M. Screening of biological activities of a series of chalcone derivatives against the human pathogen microorganisms. Chem. Biodivers. 2010, 7 (2) , 400-408.

Book, section of a book, encyclopedia or thesis: (i) Surname(s) and Initial(s) of author(s) (authors separated by semicolons), (ii) Title of chapter (iii) Title of publication (in italics), (iv) Name of the editor(s) (if applicable), (v) Name of publisher and place of publication, (vi) Year of publication.

Balci, M. Basic 1H- and 13C-NMR Spectroscopy, Elsevier, Amsterdam, 2005.

Brunet, J. J.; Neibecker, D. Catalytic hydroamination of unsaturated carbon-carbon bonds. In Catalytic Heterofunctionalization, Togai, A.; Grutmacher, H.; Eds; Wiley-VCH, Weinheim, 2001.

If a reference has more than 10 authors please use et al. after the 10th author of the reference

Huang, C.; Wang, Y.; Li, X.; Ren, L.; Zhao, J.; Hu, Y.; Zhang, L.; Fan, G.; Xu, J.; Gu, X. et. al. Clinical features of patients infected with 2019 novel coronavirus in Wuhan, China. Lancet 2020, 395 (10223), 497-506.

\section{Plagiarism Check and Ethics}

Any manuscript submitted, soon to be submitted or in press at any other journal will not be considered by Organic Communications, and it is authors responsibility to inform the Editor of Organic Communication if such event exists. If the submitted manuscript is a revised version of a previously rejected OC, the authors must indicate previous submission in their cover letter and explain the reason/changes that they made in the revised one.

The Ethical Guidelines for Publication in Journals and Reviews issued by the European Association of Chemical and Molecular Sciences are applied by Organic Communications. Authors of all the manuscripts submitted to OC automatically accept the guidelines given in the Ethical Guidelines for Publication in Journals and Reviews and the authors have to provide the ethical board approvoment document informations ( the number and date and ethical board name of ethical approval) in the main text of manuscript and related data should be available in supporting information file of manuscript, if neccesseary or requested by the editorial office. The following studies strongly needs ethical board approval eg. any of in vivo studies on any animal and human body, studies of endangered species in nature, information about the people including any kind of survey data etc. For detail please see the COPE guidelines.

Authors are encouraged to attach an authenticated report during the submission to make sure that there is no plagiarism problem. Manuscripts submitted to OC publications are routinely screened by a software to check the originality of the submitted articles. It should be noted that OC publications are committed to deterring plagiarism and self-plagiarism

ACG Publications journals use iThenticate software to check the originality of submitted manuscripts for plagiarism. If a duplication is detected by the editorial office and reviewers, the manuscript will directly be rejected. If the authors use the same sentences of their or another author's previous work with citation without quotation mark, it will still be considered as self-plagiarism and plagiarism, respectively. Organic Communication has the right of removing any article published in OC, and banning the authors submitting their studies in future if any ethical violation is identified.

\section{Copyright}

It is a condition of publication that authors vest or license copyright in their articles, including abstracts, in ACG Publications. This enables us to ensure full copyright protection and to disseminate the article, and the Journal, to the widest possible readership in electronic formats as appropriate. Authors must accept the articles published in the journal for free all around the world. To read and download published papers is free for scientific purposes.

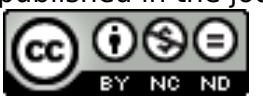

\section{Supplementary Material}

Supplementary materials could be sent together with manuscript submission such as spectra, video, Picture etc.

\section{Publication Fee}

Organic Communications (OC) is an OPEN ACCESS journal, having a primary aim of allowing the researchers to have free access to a broader scope of scientific articles. In this context, it provides the authors with affordable open access publishing 
opportunities across the world.

ACG Publications is happy to announce continuation of the publication of Organic Communications completely free of charge for two years and as OC papers are now supported by Troyasil HPLC Column Technologies. On this occasion, we would like to thank Troyasil HPLC Column Technologies (www.troyasil.com) for their great support to our scientific community. As a result of this support, there is no Article Processing Charge (APC) in Organic Communications. Submissions and publishing are free of charge for all authors for the next two years.

The authors are charged a fee for English language corrections and/or journal format corrections requested by the authors or editorial team. These services are not considered within the free publication criteria of related journals of ACG PUBLICATIONS.

\section{Withdrawal of a Manuscript}

If the authors intend to withdraw their manuscript after it has been peer reviewed, or after it has been typeset, but not yet published, you will be asked to pay according to the following:

For peer review:200 USD per article

For peer review and typesetting: 300 USD per article

\section{Proof Corrections}

The proof corrections must be done carefully by the authors. When proof corrections are returned to Journal further corrections are not allowed.

Erratum or Publisher Correction. Notification of an important error made by the journal that affects the publication record or the scientific integrity of the paper, or the reputation of the authors or of the journal.

Corrigendum or Author Correction. Notification of an important error made by the author(s) that affects the publication record or the scientific integrity of the paper, or the reputation of the authors or the journal.

Retraction. Notification of invalid results that affect the reliability of a previously published article. The original article is marked as retracted but remains available to readers, and the retraction statement notifying readers of the invalidity of the published paper is bi-directionally linked to the original published paper.

Addendum. Notification of additional information about a paper. Addenda are published when the editors decide that the addendum is crucial to the reader's understanding of a significant part of the published contribution. Addenda include Editorial Expression of Concern, which is an editorial statement alerting our readership to serious concerns with the published paper. Editorial Expressions of Concern are typically updated with another amendment once further information is available. The editors may request additional information after publication of the article from the authors and it can be available on the page of the article.

\section{Peer Review Policy}

All published research articles in Organic Communications have undergone rigorous single blind peer review, based on initial editor screening and anonymized refereeing by expert referees. 


\section{Contents}

Review Article

Nataliya Korol, Mikhailo Slivka and Oksana Holovko-Kamoshenkova

Cycloaddition reactions of 4-phenyl-3H-1,2,4-triazole-3,5(4H)-dione (PTAD) and 4-methyl-3H-1,2,4-triazole-3,5(4H)-dione (MTAD): A short review - p.146-154

Original Article

K. Pushpa Kumar, Reddi Mohan Naidu Kalla, Mavallur Varalakshmi, Chintha Venkataramaiah, K.Swetha Kumari, Jayakumar Kannali, D. Venkatramana Reddy and Chamarthi Naga Raju

Synthesis, spectral characterization, antimicrobial activity and docking studies against DNA Gyrase-A of new

4-chloro-3-nitrobenzene sulfonamide derivatives - p.155-164

Original Article

Sümeyye Turanlı, Azize Gizem Uslu and Aysun Özdemir

Synthesis of novel potential ROCK inhibitors and their antimigratory effects - p.165-174

Original Article

Cenk A. Andac

Facile microwave synthesis of a novel phenothiazine derivative and its cytotoxic activity - p.175-183

Original Article

Hülya Yanık, Sümeyra Ayan, Atilla Akdemir, Ömer Erdoğan, Cem Bülent Üstündağ, Özge Çevik and Özgür Yılmaz Synthesis, anticancer activities and molecular modeling studies of some 2-aminonaphtho[2,3-d][1,3]thiazole-4,9-dione derivatives - p.184-193

Communication

Parshuram M. Pisal, Vinod T. Kamble, Ravi Varala and Pradip B. Gujarathi

Efficient one-pot three-component synthesis of $2 \mathrm{H}$-indazole [2,1-b]phthalazine-1,6,11(13H)-triones at room temperature p.194-201

Short Communication

Şule Şahin Ün, Ramazan Altundaş and Ahmet C. Gören

Synthesis of $\gamma$-glutamyl $\beta$-cyanoalanine precursor - p.202-206 